\title{
Aspects of English Language Teaching
}

\author{
E. Madhavi \\ Department of English St Martin's Engineering College, Dhulapally, Secunderabad, Telangana
} (INDIA)

\begin{abstract}
The main focus of the paper is on the individual skills of the language use. It also deals with definitions of these skills, the sub skills or components of each skill, and ways pertaining to the learning and teaching of the skills. One of the key principles of communicative pedagogy is to teach skills in an integrated manner. Assumptions of teaching and learning inherent in ELT class room are introduced so that a mind set or focus, necessary for the study of the principles of methodology is encouraged. It makes us know about basic issues in the field of English language teaching to improve teaching practices, rather than an orientation to the discussion of academic issues for the academic purposes. The paper introduces us to the activity of theorizing about the classroom. This means the principles of language teaching are arrived through analysis will be made by the learner through his own teaching practice but much of the analysis will be made on the basis of conclusions arrived by the theorists in the field. This is nothing but involving the behaviors of the participants of the teaching-learning process in the curriculum.
\end{abstract}

Keywords: ELT (English language teaching); LSRW (Listening, Speaking, Reading and Writing); IRF (Initiating Responding Feedback)

\section{Introduction}

The major components of teaching-learning process are the classroom, the learner and the teacher. This is not to say that these three components are all that there is to the teaching- learning process. As we go long, we also come across different aspects required for ELT but a discussion of the classroom, the learner and teacher is as good starting place as any other. It is just an organization of ideas from the familiar to new and from the old to the new. All methods don't claim to teach the best methods of teaching our class, rather they claim to help us think of the best methods for teaching our class, and they also present us with a range of options in methodology from which we can choose in order to teach in systematic and informed ways. Methods in other ways are concerned with the theoretical issues and principles underlying teaching in the classroom. "Theory in language teaching and learning can be defined simply as the thought underlying language teaching" [2]. In other words it is nothing but the thoughts of the individual teacher and the thoughts of theorists, towering personality in education and researchers representing different frame works and schools of thoughts.

\section{Context}

Thoughts underlying theories can be categorized according to the perceptive or points of view which they are made by like- minded people. Some assumptions on language teaching focus on the form of language while others take on the perspective of sociological organization or psychological learning process [1]. We can say that language teaching is informed by supporting disciplines like linguistics, psychology, Education, literature, curriculum theory, sociology and etc. It is appropriate to draw our attention to a fundamental distinction between teaching and learning.

\subsection{Teaching}

Teaching involves the curriculum and the ways in which is organized in schools for instructional purposes. Teaching is what we do in schools, in an organized way for pre-determined learning out comes [2].

\subsection{Learning}

Learning on the other hand is something that happens inside the mind of the learner [2]. This could be the result of planned instruction in schools. Learning in other words can occur ever without systematic instructions planning. Often this kind of informal learning could be even more effective than learning through planned instruction. We can think of numerous examples in language learning especially if we consider how a child learns the mother tongue. An informal language learning situation is one where language is not taught or learnt for grammar but for communication [1]. A child growing up learns to use language functionally i.e. to get things done, or to express himself / herself. Thus expressional could be transactional or self- expressive in nature. A small child spends time in prattle but even prattle has a purpose in itself as play has. For it is really 
through easy, anxiety five tryouts- like prattle and play- that the child is developing language skills. So the child when it uses language in different contexts, finds out the appropriate language behavior can cause result and obtain responses. Thus by using language, the child develops language skills. We can say that, when a learner uses language the language used becomes his/her own use implies assimilation and consolidation of what is learnt.

The formal learning system is very different from informal learning system. Here, we are referring to organized learning program. But we need to look at these differences more carefully while analyzing the difference we ourselves has to put a question (1) Are we teaching English so that students can pass examination on the context of the readers? That is do we see English as a 'portion' to be "covered'? Or do we see English as language skills to be mastered? Well most of us say it is a language skill to be mastered but secretly we might believe that it is a 'portion' to be covered. We might feel justified in choosing either of these objectives but we should be clear about our teaching objective (1) for exams or (2) for developing learning skills in the learner then surely it will influence our teaching practice and we ourselves question?

Why do we teach English?

What do we teach in English?

How do we teach English?

If we don't fulfill all these three objectives the student won't become autonomous learner. It will help them only to pass the examination but in long run they will be the failures. In olden days the whole focus on language teaching was on vocabulary development and sentence development but today focus on language teaching has shifted to skills development (LSRW) i.e. functional use acquired more importance. That is we have started looking language teaching to socio - cultural settings and not only at language form and grammar.

Especially in informal learning situations, situations are not structured [3]. Learning takes place but not through the organized planning of a educational agency. Indeed sometimes the classroom is not in a room. Thus Rousseau's educational experiences with Emile, describe learning experiences, where nature taught a child and neutered him in experience, wisdom and knowledge. Emile learnt when he wanted to, and whatever aroused his fancy, as he walked in the woods with his mentor and guide. Emile didn't learn in doors but outside in the lull of nature. Then Paulo Frere's described in his pedagogy of the oppressed (1972). Where he helped farmers to get illiterate was also conducted outside the class room walls. Even Tagore's Educational Sanctuary at Shantiniketan proved that Informal learning motivates and creates good learning conditions. Class room also plays vital role in teaching- learning process. Studying a class room with variable proved to be problematic for researchers. Several experiments ex; Shearer\& Wertheimer (1964) and Chastain and WXRDEHAFF (1968) THE GUME Project (Lenin 1972) the Pennsylvania Project (Smith 1970) conquered teaching methods in the empirical scientific experimental mode by controlling one variable [3].

These experiments looked at changes in teaching method in real- life situations and operated with teaching method as the main category of comparison. Thus the audio-lingual method was compared to the grammar translation method, immersion methods were compared to non - immersion methods etc. These methods however were not theoretically distinct from each other and the experiments were not conclusive. It was difficult therefore to compare one teaching method with the other.

Bane's analysis of classroom discourse was perhaps as the first to be made in the U.K. on what he called the microcosm with interacts with the social macrocosm of which it is apart. To Barnes, the study of language in the classroom was to study both the learning processes and some of the internal and external constraints on them. In his essay 'The Language in the secondary classroom, Barnes (1969) has gives us a sample of the tools he has used for the analysis of classroom data. He was one of the first in classroom research to point to the nature of teacher talk and student talk [4].

This area of analysis, classroom interaction, has now been greatly developed since the times of Barnes. Mehan (1979), in the U.S. has given a good analysis of classroom and R.Allwright (1983) has presented recent developments in this area of research [3].

These are the tools then, available to us for examining the classroom and the amount of student and teacher talk. Most analysis of classroom interaction moreover, come up with 'IRF' structure in the classroom, where the teacher it is clear, makes all the initiating moves(I) to which students respond(R) and to which the teacher gives feedback [3]. The CBSE 'Course A' books refer to the IRF structure as the "two thirds" rule this means that teachers talk $2 / 3 \mathrm{rds}$ of time in a class period, which time it is felt should be reduced for communicative skills to take place and the teacher should try to discover the dynamics of method or techniques, how in interaction things work in optimal conditions, before we try to implement these techniques within the constraints of real teaching conditions. We shouldn't initially expect any results from trying out something new in a large apathetic class. Rather we need to address the apathy and boredom first, and motivate students to work with us before we try out new methods in the real large class. 
The second component of the teaching - learning process the teacher. In this we come across some belief systems and attributes to problems in teaching. We will also come to the skills of facing problems in the classroom and of utilizing them for both learner and teacher development. Being a teacher we give most importance to the number of years of teaching experience, because it is often thought that a teacher, old in teaching experience, is a good teacher. Well, this is not really true, as we can see if we look at some of the younger teachers that we know. On the other hand, these is really nothing like experience and it is often the older teacher, who is able to cope with a critical situation in the class, and who is better able to get results and so on. It also boils down to the quality of experience perhaps where working and teaching is a growing experience and not one where mistakes are contributed again and again. Experience should help us to grow, not keeping crystallized in a particulars pattern of behavior that is, and experience does help some people to grow but for other 'experience' only means repeating the same behavior over many years, regardless of outcomes.

\section{Conclusion}

The quality of teaching experience is importance as we have said before. It is also important to recognize our attitudes to students, to what learning is, and to what language learning is this depends strangely enough, on our attitude to many things in life to how we perceive knowledge. For instance, is "knowledge" to be perceives as relative to the learner, to be picked up according to need and, or it is something to be transmitted to the learner by the teacher [5].

We have to perceive our self, our attitudes and belief systems, and then to see these is relation to the belief systems of others in the society.

This helps us to be an informed teacher. Many teachers are negative in focusing the problems that we come across teaching because we are working at our teaching professions unilaterally without listening to the problems or without using the feedback we have received on our classes or without considering the individual learners in the classrooms, the slow learner, the fast learner, the disadvantaged learner and so on. Acknowledging the presence of problems in teaching only results our ability to confront a problems. The presence of in teaching is a daily state of living for the conscientious teacher. So our ability, willingness, attitude to dual with them contributes to the kind of self evaluation. It also leads us to success as a teacher. Always remember that problems in teaching mean that we are teaching. If we have no problems start concentrating and so on we will find them. This is important for quality improvement in teaching. Research in teaching means being able to problematic. If we do this hen we will be able to find worthwhile solution. Cooking positively at problems says thematically means that we are theorizing on the class room.

Mike Wallace (1991) talks of the reflective model in teacher education, where teachers reflect on experiential knowledge reflecting on teaching experiences helps us to grow. It helps us to theories on our practice, think about something happened the way it did, how it could be improved etc. unless we reflect on our outcomes we will never learn from our mistakes [6].

These have been a recent modification to the whole nation of reflecting on teaching. It has been suggested that the term interpreting teaching is more efficient, since this term reflects thoughts and action (Holliday 1994).

Then coming to the resources of teacher. Resources are nothing but the tools available. The syllabus, textbook, black board and teaching aids are the tools available for the teacher but these tools should be most usefully exploited for our purpose so that we can be more constructive in our attitude to teaching [7].

\section{Reference}

[1]. Little wood. W.T. Foreign and second language learning . Cambridge university press. (1964).

[2]. Stern. H.H. Fundamental concepts of language teaching. Oxford university press. (1983).

[3]. Allwright. R. Classroom centered research on language teaching \& learning: A brief historical over view. Tesol quarterly 17/2: 191 201. (1983).

[4]. Barnes Douglas et al. Languge, the learner and the school : A research report with a contribution by James Britten and a discussion document prepared by Harold Rosen on behalf of the London Association for the teaching of English. (1969).

[5]. Holt John. How children fail. Harmonds worth, Penguin Education. (1971).

[6]. Illich Ivan. Deschooling society London. Calder \& Boyers. (1974).

[7]. Wallace M. Training foreign language teachers. A reflective approach CUP. (1991). 